\title{
Filosofía teórica y práctica en Ptolomeo, Almagesto 1.1
}

Theoretical and practical philosophy in Ptolemy's Almagest 1.1

Pedro Redondo Reyes

Universidad de Murcia, España

predondo@um.es

(D) https://orcid.org/0000-0002-5426-3848

\section{Resumen:}

En Almagesto 1.1, Claudio Ptolomeo presenta la división clásica de la filosofía en teoría y práctica, apoyándose en la tradición peripatética pero con elementos diversos en su expresión. En esta división, Ptolomeo privilegia el ámbito teórico y defiende el estudio de las matemáticas como la disciplina que conlleva una mejor predisposición del alma hacia la belleza y las virtudes éticas. En el análisis del pasaje del proemio, se compara el tratamiento ptolemaico de la cuestión con los de Arquitas, Alcínoo y otros autores. Palabras Clave: Ptolomeo, Almagesto , División de la filosofía, Matemáticas, Ética.

\section{Aвstract:}

In the Almagest 1.1, Claudius Ptolemy presents the classical division of philosophy into theory and practice, based on the Peripatetic tradition with different elements in its expression. In this division, Ptolemy privileges the theoretical realm and defends the study of mathematics as a discipline that entails a better predisposition of the soul towards beauty and ethical virtues. In the analysis of the preface, Ptolemy's treatment of the issue is compared to those of Archytas, Alcinous and other authors.

Keywords: Claudius Ptolemy, Almagest, Division of philosophy, Mathematics, Ethics.

En los últimos años se ha despertado un gran interés por las aportaciones filosóficas de la obra de Claudio Ptolomeo, un autor que había atraído la atención, tradicionalmente, por su obra astronómica y astrológica. Pero la posición filosófica de este autor alejandrino ya fue estudiada desde finales del XIX por Boll (1894) y en las décadas siguientes por Schönberger (1914) y Lammert (1922), quienes insistieron en el carácter ecléctico de los elementos filosóficos, sobre todo desde un acercamiento al léxico y las fuentes empleadas. La idea heredada era la de un autor con elementos de la última Estoa aderezados con planteamientos dispersos de Aristóteles. Recientemente la crítica ha retomado el estudio de los textos más claramente filosóficos (en primer lugar, Sobre el criterio, pero también algunos capítulos de la Harmónica y también el Almagesto), señalando el vínculo platónico en su inclinación hacia la matematización de la ė $\pi \_\tau \eta \dot{\mu} \mu$.

Las ideas filosóficas que pueden extraerse de la obra ptolemaica están mediadas por el tipo de actividad que desarrolló, característica de la ciencia alejandrina. Un caso paralelo es el de Galeno, un científico muy preocupado por el encaje filosófico de su tarea en el marco de las tendencias filosóficas de la época, con una importante presencia de cuestiones epistemológicas. Precisamente a ellas dedica Ptolomeo Sobre el criterio, que ha sido considerado, en la secuencia de sus obras, como el primero de sus textos (Swerdlow, 2004, p. 175). Es notable que, en dicha secuencia, Harmónica y Almagesto sean considerados inmediatamente posteriores a Sobre el criterio: en ellos es donde Ptolomeo vuelve a la filosofía como antesala del objeto respectivo de cada tratado. Podemos concluir, por tanto, que (al menos en el corpus conservado) es en su producción temprana donde queda fijado el marco filosófico.

Feke (2018) es un hito importante en el estudio de las ideas filosóficas y la trabazón que estas desarrollan a lo largo de los tres tratados mencionados. A Feke había precedido Taub (1993), que revisó la confluencia en la obra astronómica de Ptolomeo de las ideas peripatéticas junto a las del platonismo antiguo y medio y la Estoa. Taub describió a Ptolomeo como un ecléctico, en la línea de la descripción que, desde E. Zeller, la 
filología y la historia de la filosofía han proporcionado sobre el pensamiento del siglo II d. C., a partir de las noticias que sobre Potamón de Alejandría provee Diógenes Laercio (1.21).

Desde el punto de vista de sus aportaciones filosóficas, el contexto en que se movió Ptolomeo es el del comentario, la forma en que las escuelas filosóficas se desarrollaron a partir de la época helenística y que alcanzó su plenitud en época imperial, coincidiendo significativamente con el auge del aticismo y la vuelta a la fidelidad de la tradición. La génesis de este género presenta más problemas en el ámbito peripatético que en el platónico, dadas las noticias sobre la suerte de los escritos de Aristóteles, pero, como señaló Jonathan Barnes (2007, p. 548), una historia de la epistemología peripatética debería contemplar detenidamente la obra ptolemaica (y no solo el Criterio); desde este punto de vista, Ptolomeo pertenece, en la historia de la recepción del aristotelismo, al período inmediatamente anterior a Alejandro de Afrodisias. Es importante señalar que Aristóteles es citado en el proemio del Almagesto (1.1) para justificar el estudio matemático del cosmos a partir de la Metafísica; solo Platón comparece como filósofo ilustre en el corpus conservado. ${ }^{1}$ Y si se muestra un buen conocedor del Platón del Timeo, el conocimiento que tuviera Ptolomeo de primera mano de la Metafísica es dudoso ${ }^{2}$ (hay ecos, sin embargo, también de Categorías, Ética a Nicómaco y Sobre el alma en el corpus ptolemaico); además, Ptolomeo mantiene semejanzas notables con Alcínoo y con Arquitas, como se verá seguidamente. El problema de la orientación filosófica es aún más complejo en el caso de Sobre el criterio, donde Ptolomeo expone sus planteamientos epistemológicos (objetivo preferido del escepticismo), una discusión que viene de época helenística en la que la mayoría de las escuelas han adoptado ya un vocabulario filosófico común y donde la crítica ha visto influencias decisivas de toda índole. ${ }^{3}$

En las líneas que siguen, nuestro objetivo será el examen de un pasaje del Almagesto (1.1) donde Ptolomeo divide la filosofía en sus aspectos teórico y práctico, y las consecuencias que extrae de tal división. Omitiremos, pues, por considerar que ya existe un buen tratamiento de la cuestión (Feke, 2018), la división que en el mismo proemio el alejandrino hace de la parte teórica (en teología, matemáticas y física), de evidente raíz aristotélica pero extendida en la época de Ptolomeo. ${ }^{4}$

\title{
Filosofía práctica y teórica: Almagesto 1.1, 4.7-18 Heiberg
}

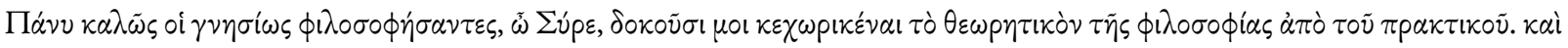

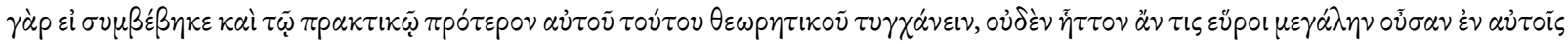

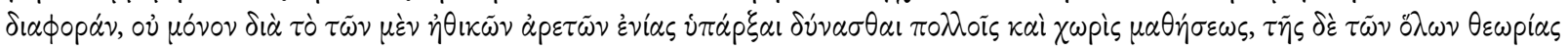

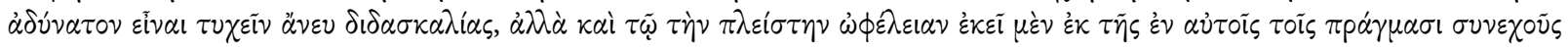

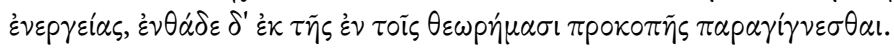

Me parece, Siro, que los auténticos filósofos distinguen correctamente, en la filosofía, entre la parte teórica y la práctica. Pues incluso si se diera que la práctica fuera anterior a la teórica, uno no dejaría de encontrar que existe una gran diferencia entre ambas, no solo porque algunos pueden tener virtudes éticas sin aprendizaje (mientras que es imposible alcanzar el conocimiento teórico de las totalidades sin instrucción), sino también porque logran su mayor provecho la una [la práctica] a partir de la actividad continua en las mismas acciones, la otra [la teórica] a partir del progreso en la teoría. ${ }^{5}$
\end{abstract}

Fue C. Tolsa (2013, p. 274) quien señaló que el comienzo del proemio tiene ecos verbales y sintácticos con el fr. 1 de Arquitas (47B1 D.-K. = fr. 1 Huffman, 2005), por lo que debe ser considerado como su fuente primaria; no es de extrañar, dada la autoridad que este pitagórico tenía para el alejandrino:

Me parece que quienes se dedican a las ciencias han distinguido bien, y no es sorprendente que reflexionen correctamente sobre cómo es cada una de las cosas; pues, habiendo hecho distinciones acertadas sobre la naturaleza de las totalidades podrán ver correctamente cómo son las cosas en sus partes.

La división de Arquitas no está clara, pues la relación entre el plural $\tau \tilde{\omega} \nu$ ò $\lambda \omega \nu$ y $\kappa \alpha \tau \dot{\alpha} \mu$ śpos ha sido interpretada en varios sentidos: según Huffmann (2005), "in each science, there is a whole or a set of wholes, which those concerned with the sciences distinguish, and that, because of their good discernment of these 
wholes, they are able to see well how things are in their parts" (p. 59). Ptolomeo recoge la noción de totalidad entendiéndola como el objeto total de la filosofía teórica (que después dividirá en teología, matemáticas y física), pero con la posterior distinción y la contraposición con la filosofía práctica introduce las ideas aristotélicas sobre el esquema de Arquitas.

Ciertamente, la distinción entre filosofía práctica y teórica ya estaba presente en Platón, ${ }^{6}$ y Aristóteles, en varios lugares del corpus, añade la parte productiva. ${ }^{7}$ Sin embargo, como Feke (2018, p. 10) ha señalado, ambos filósofos parten de supuestos diferentes en cuanto a la prelación y consideración de tales distinciones (sobre todo a la dependencia de la praxis respecto a la teoría). Estas diferencias parecen haber sido debatidas en los siglos siguientes, hasta el II d. C.; por su parte, Ptolomeo también alude a la distinción entre filosofía teórica y práctica en Harmónica 3.6 y Sobre el criterio 11. Ya Boll (1894, pp. 70 y 108-109) apreció el origen aristotélico de tales divisiones y subdivisiones del Almagesto; ahora bien, en Metafísica coexisten una división bipartita al modo ptolemaico en 993b 20, y otra tripartita en 1025b 25 ss. Pero Ptolomeo acepta una división que no es tanto aristotélica cuanto, simplemente, aceptada por los peripatéticos, si seguimos a Ps. Plutarco, Opiniones de los filósofos 874F 2 (Diels, 2010, p. 273). Por lo demás, en Harmónica la parte práctica la divide en tres aspectos (ético, doméstico y político, 98.9), que no tiene, con esta forma, un directo origen aristotélico $^{8}$ y sí paralelos con Alcínoo (Didascálico 3.3) y otras fuentes tardías identificadas por Raffa (2002) y Dillon (1993).9 Estas fuentes sugieren que Ptolomeo no está utilizando a Aristóteles para distinguir entre una ảpxท́ teórica y otra práctica. ${ }^{10}$

Efectivamente, la crítica ha señalado algunas de las fuentes más o menos contemporáneas al alejandrino que estarían relacionadas con el modo de distinguir liminalmente los ámbitos filosóficos en un tratado como el Almagesto. Aunque la cuestión remonta a Aristóteles e incluso a la Academia antigua, autores de compendio o comentario como Alcínoo o Aspasio tienen paralelos significativos. Así, Alcínoo presenta una división en filosofía teórica y práctica (Didascálico 3.3-4) ${ }^{11}$ que contiene también la segunda tríada ptolemaica; en 24.4 hay, asimismo, una división del alma en una parte racional y otra afectiva: la primera de ellas "es el cultivo de la razón mediante la instrucción" ( $\delta \delta \delta \sigma \kappa \alpha \lambda i \alpha)$, mientras que la segunda se desarrolla "por la ejercitación del carácter". ${ }^{12}$ Este texto bien puede ser la fuente de Ptolomeo o el testimonio de una fuente común. Mientras que tratados como los del Ps. Andrónico (Afectos 2.4) están detrás de la elaboración ptolemaica de las virtudes en Harmónica $3.5^{13}$ y son el material que utiliza el alejandrino, el subtexto de estas elaboraciones es Metafísica 993b 20 y Ética a Nicómaco 1142a 10. Feke señaló la novedad que presenta Ptolomeo en el proemio: no solo distingue virtudes morales e intelectuales según su respectiva adquisición (hábito o instrucción), sino que se sirve de ellas para distinguir, a su vez, filosofía práctica y teórica. Esta concepción o simplificación se encuentra también en Alcínoo, cuando presenta las formas respectivas de desarrollarse las dos partes del alma, la racional y la afectiva, con ecos en el texto ptolemaico, en el texto citado (Didascálico, 24.4).

La simplificación viene no solo del hecho de identificar ambas partes del alma con el tipo de ciencia respectiva (cf.Didascálico 3.3), sino de asumir que el ámbito de los $\pi \alpha \theta \eta \dot{\eta} \mu \alpha \tau$, es decir, el que está relacionado con las virtudes, no está relacionado con la instrucción y sí, tan solo, con la práctica (cf. Almagesto1.1,

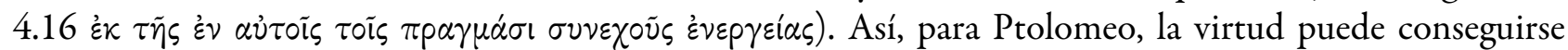
“sin instrucción” pero necesita de actividad continua. Taub (1993, p. 21) cita Ética a Nicómaco 1095a 13 para defender que Aristóteles -al contrario que Ptolomeo- estima necesario el estudio en la virtud política, mientras que Boll (1894, pp. 70-71) citó Ética a Nicómaco 1103a 14-18 y su división entre virtudes intelectuales y éticas con el procedimiento de adquisición respectivo, paralelo en Ptolomeo:

Como existen dos clases de virtud, la dianoética y la ética, la dianoética debe su origen y su incremento principalmente a la enseñanza, y por eso requiere experiencia y tiempo; la ética, en cambio, procede de la costumbre. ${ }^{14}$

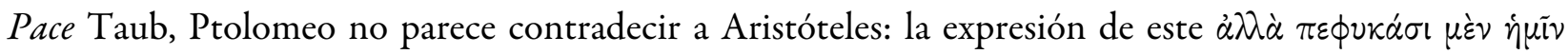

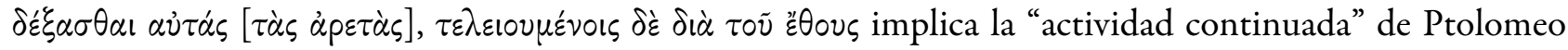




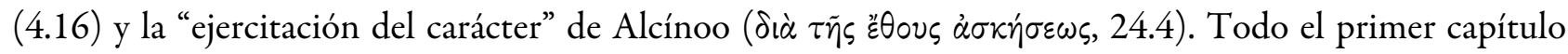
de Ética a Nicómaco II es el subtexto, simplificado ahora, de la idea ptolemaica. ${ }^{15}$ Lo que hace Ptolomeo en 4.9-10 es señalar que tanto si hay dos tipos de virtudes, intelectuales y éticas (siguiendo a Aristóteles) como si se asume que las éticas pueden ser entendidas teóricamente, entonces la consecuencia (la necesaria

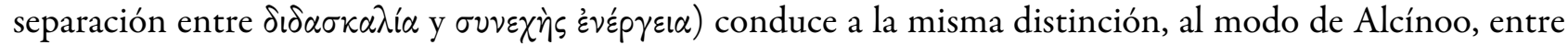
filosofía teórica y práctica, con idénticos requerimientos (cf. Didascálico 2.1). En estas líneas del proemio, Ptolomeo condensa la distinción aristotélica entre tipos de virtudes y la equivalencia, señalada por Feke, entre filosofía práctica-ejercicio y filosofía teórica-instrucción. ${ }^{16}$ No nos parece tan claro que Ptolomeo distinga en Almagesto, como sostiene Feke (2018), "between the intelectual and moral virtues according to whether they are acquired by instruction or habit” (p. 58), pero sí lo hace en Harmónica 3.5-6, donde equipara las distintas virtudes a las partes del alma (en función de los tipos de consonancia): a la parte racional le atribuye siete. ${ }^{17}$ Se ha señalado que en esto Ptolomeo sigue la tradición del platonismo medio, aunque la distribución de virtudes según las partes del alma ya estaba preparada por Aristóteles en Ética Eudemia 1220 a 5-12 y tuvo desarrollos estoicos. Pero lo importante es que en Harmónica 3.6 el alejandrino afirma que "las virtudes son comunes a los tres géneros" (físico, matemático y teológico, las partes de la filosofía teorética); sin embargo, no dice expresamente en el proemio que haya dos tipos de virtudes, solo que es posible considerar las virtudes éticas desde un punto de vista teórico.

Si Alcínoo, como se ha visto, conecta las partes del alma con las formas de adquisición de las respectivas virtudes, en Aspasio (comentarista de Aristóteles) se comprueba que también las virtudes intelectuales se adquieren por instrucción. ${ }^{18}$ En su Comentario a la Ética nicomáquea (37.12) sitúa entre este tipo de

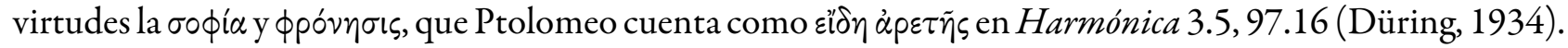
En el proemio del Almagesto (4.13), al referirse a las virtudes éticas, el alejandrino parece hacerse eco de la afirmación de Aspasio de que las virtudes intelectuales pasan por la instrucción (37.23, ö $\tau \iota \mu \dot{\varepsilon} \nu$ o $v$ ai

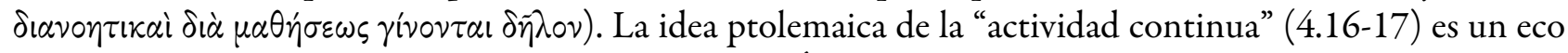
del hábito reiterado (Aspasio parafrasea a Aristóteles, Ética a Nicómaco 1103 b 13 ss.):

Las virtudes éticas tienen su origen sobre todo en el carácter y su desarrollo; pues los hombres, en su trato con los intemperantes, se convierten en intemperantes (Com. Ética a Nicóm.37.23-38.1).

Ptolomeo, pues, aprovecha el material del melieu filosófico tanto peripatético como medioplatónico para configurar un esquema basado en la equivalencia entre tipos de filosofía y adquisición de las respectivas virtudes (en Almagesto), y otro distinto basado en la equiparación entre las distintas partes del alma y sus respectivas virtudes (en Harmónica). ${ }^{19}$ Que este último tipo de esquema era habitual lo muestra Galeno,

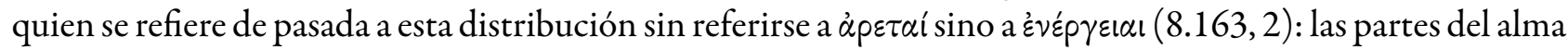

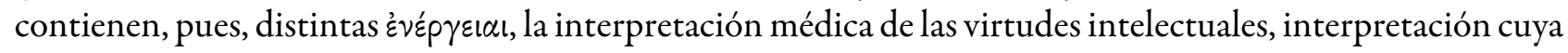
última raíz es la propia consideración aristotélica de la virtud como actividad. ${ }^{20}$

\section{La ACCión de la representación: ALmagesto 1.1, 4.18-5.7}

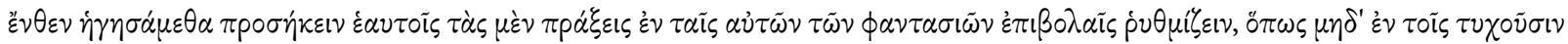

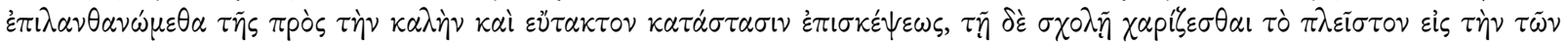

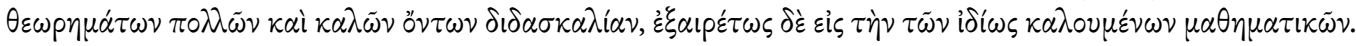

Por ello consideramos que nos conviene ordenar las acciones en la proyección de las representaciones de aquellas, para que no olvidemos, en ninguna circunstancia, orientarnos hacia una disposición hermosa y ordenada y dedicar el mayor tiempo posible en la instrucción de la teoría, que es mucha y hermosa; sobre todo a la que se llama matemáticas.

La conclusión de la configuración dual de la filosofía es la recomendación de ordenar las acciones prácticas conforme a la "proyección de las representaciones". ${ }^{21}$ Se trata, de nuevo, de un texto obscuro: no solo por 


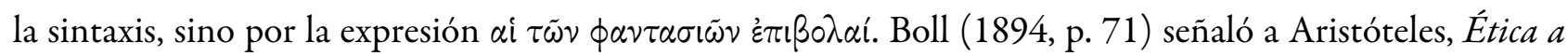
Nicómaco 1104a 6-8 como subtexto con razón, pero también a la $\chi \rho \tilde{\eta} \sigma \iota \varsigma \tau \tilde{\omega} \nu \phi \alpha \nu \tau \alpha \sigma i \tilde{\omega} \nu$ de Epicteto como un elemento estoico de la teoría del conocimiento ptolemaica. ${ }^{22}$ En el caso de la expresión en cuestión, Feke (2018, p. 64) ha indicado el paralelo con Casio Longino (Retórica, p. $572.11 \mathrm{Walz}, 1863$ ), e insiste en que tanto Ptolomeo como Casio Longino están utilizando un vocabulario compartido por distintas escuelas

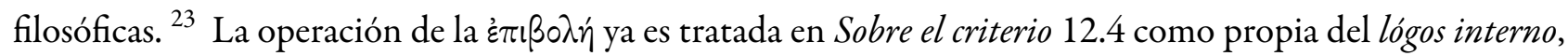
donde esta aplicación con los criterios simples y no silogísticos da lugar a la mera opinión. A la vista de Sobre el

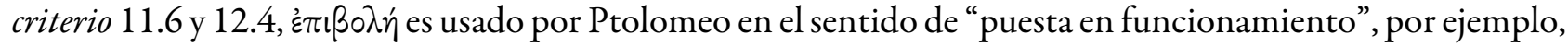

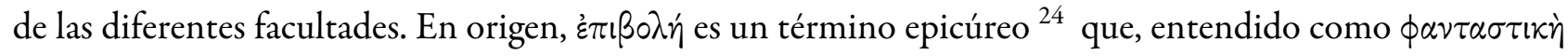

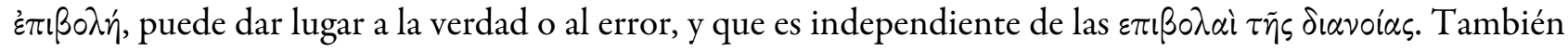

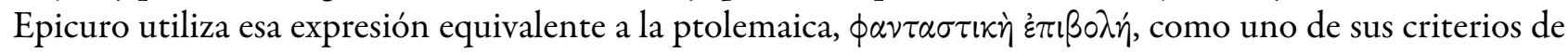
conocimiento, y que implica una imagen ( $\dot{\varepsilon} v$ દikóvı, Diógenes Laercio 10.51) provista por los sentidos. ${ }^{25}$

Ahora bien, respecto a la idea de un léxico filosófico compartido y poco marcado, hay que señalar que en Sobre el criterio 4.3-6, un pasaje relativo al origen del lenguaje, Ptolomeo sigue muy de cerca a Epicuro, incluso con paráfrasis. Pero el plural $(\phi \alpha \nu \tau \alpha \sigma i \tilde{\omega} \nu)$ en la expresión ptolemaica y su uso indican que, como elemento integrado en el esquema del criterio de verdad, Ptolomeo va más allá de la fidelidad al propio Epicuro. Feke (2018, p. 64) ha señalado que el término, utilizado en plural, tiene en Ptolomeo el significado de "impresión de los sentidos", como se deriva de Sobre el criterio 10.6 (este es el sentido que le daba Crisipo), mientras que en singular equivaldría a la transmisión al intelecto de dicha impresión. La expresión ptolemaica tendría, pues, el sentido de una "focalización de las impresiones", que deben ser las que estipulen ( prácticas, teniendo en cuenta que la $\phi \alpha \nu \tau \alpha \sigma i \alpha$ es parte del criterio de verdad para Ptolomeo.

Feke argumenta (basándose en Aristóteles, Sobre la memoria 450b 11 ss.) que en la expresión ptolemaica

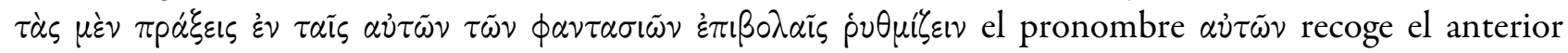

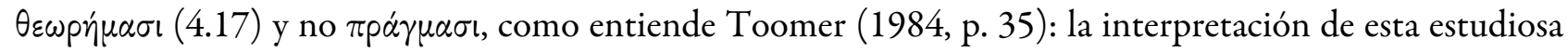

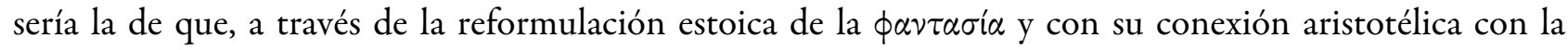
memoria, Ptolomeo establece la necesidad de que la acción práctica, respecto a la manifestación de las virtudes, venga mediada por la previa actividad contemplativa; en esta pretensión, el paralelo más significativo es, de nuevo, Alcínoo (Didascálico 2.2), que tiene como precedente la idea platónica de implantar en la vida práctica lo que el filósofo "ve". ${ }^{26}$ Ciertamente, este paralelo es persuasivo, dado que este autor conecta la

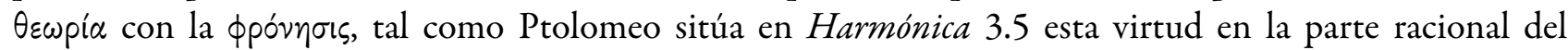
alma. ${ }^{27}$ La novedad, pues, consistiría en la posibilidad de que la $\phi \alpha \nu \tau \alpha \sigma i ́ \alpha$ contuviera también teorías o teoremas (y no solo objetos o hechos). Esta interpretación -que necesita del doble sentido de $\phi \alpha \nu \tau \alpha \sigma^{\prime} \alpha$ tiene la ventaja de iluminar la subsiguiente defensa de una vida contemplativa, pero a costa de forzar el valor pronominal de $\alpha \dot{\tau} \tau \tilde{\omega} \nu$. Este valor sintáctico está justificado si se entiende que $\tau \tilde{\omega} \nu \phi \alpha \nu \tau \alpha \sigma i \tilde{\omega} \nu$ requiere de un objeto, pero no es lo que se desprende de la paráfrasis del comentarista Teón (Comentario al Almagesto 321, 5-8):

Así pues, al existir estas diferencias (me refiero a la praxis y a la teoría), y al suponer que es necesario que aquel que vive adecuadamente se atenga a una y otra, él [Ptolomeo] afirma hacerlo -atenerse a una y otra- al "ordenar las acciones en la misma proyección de las representaciones".

Aquí, “en la misma proyección de las representaciones” muestra el pronombre en un uso atributivo; Teón se extraña, más bien, de que Ptolomeo no diga que se debe comenzar eligiendo la acción para, a continuación, realizarla de manera medida $(\varepsilon \dot{p} v \dot{\theta} \mu \omega \varsigma)$. ${ }^{28}$ Pero a pesar de esta paráfrasis, Ptolomeo, desde 4.9 ss., examina la consideración teorética de la filosofía práctica, y un fragmento del platonizante Eudoro refuerza la idea de que la acción debe venir mediada por la reflexión previa, significativamente con el término epicúreo mencionado: refiriéndose al valor de la acción que se va a elegir, afirma este autor: 
“(...) no es posible que el impulso sea razonable si no viene acompañado de la teoría; la teoría es un examen de la acción y una suerte de juicio a partir del razonamiento sobre aquella; en segundo lugar, agregar ( $(\dot{\pi} \pi \beta \alpha \lambda \varepsilon i v)$ adecuadamente el impulso a aquello que se ha pensado"(fr. 1 Mazzarelli, 1985). ${ }^{29}$

El impulso (ópuń) es un concepto de procedencia estoica ${ }^{30}$ que ha sido integrado en el vocabulario común filosófico. Según Ptolomeo (Sobre el criterio 16.3), está dirigido por el órgano donde se ubica la facultad intelectiva, el cerebro, siguiendo la tradición estoica de la obediencia del impulso a la razón; ${ }^{31}$ el cerebro es, como se ha visto, lo más cercano a la vista (junto al oído, el sentido más racional).

\section{Consecuencias Éticas de las matemáticas: Almagesto 1.1, 7.17-24}

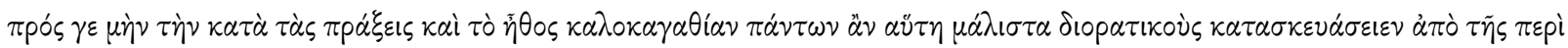

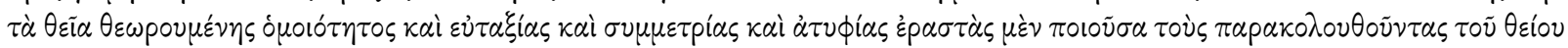

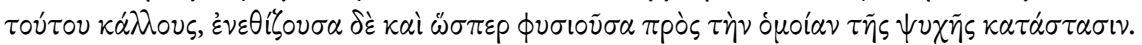

Estas [las matemáticas], respecto a la conducta correcta en las acciones y el carácter, más que cualquier otra ciencia pueden contribuir a que los hombres vean con mayor claridad debido a la constancia observada en los objetos divinos, al orden, la proporcionalidad y la simplicidad; y convierten a quienes las estudian en enamorados de la belleza divina, habituándolos y volviéndolos susceptibles de alcanzar una disposición semejante del alma. ${ }^{32}$

Tras unas consideraciones sobre las tres disciplinas de la filosofía teórica (teología, matemáticas y física) que constituyen una paráfrasis con modificaciones importantes de Aristóteles, Metafísica 1025 b 25 ss., Ptolomeo retoma, antes del final, el valor de las matemáticas (entendidas como astronomía matemática) para la dimensión práctica del ser humano, conducente a la kalokagathia. En realidad, aquí se retoma la idea de

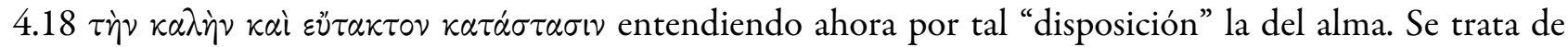
asegurar la correspondencia efectiva entre las características de los objetos matemáticos -aquí astronómicosy la disposición del alma, una idea que no es ajena al pensamiento griego, sobre todo en la música de tendencia pitagorizante. Se ha señalado que la idea de una semejanza con lo divino en Ptolomeo procede de Platón

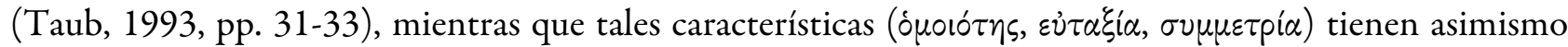
un aire aristotélico (cf. Metafísica 1078a 36-b2); las volvemos a encontrar en Harmónica 3.4, 94.24-95.3, y probablemente su aparición en Ptolomeo está relacionada con esta idea divulgada en su tiempo, como se desprende de Alcínoo, Didascálico 28 y $30 .{ }^{33}$ Esta disposición basada en el orden sería, pues, el télos de la filosofía teórica realizada a través de la astronomía y la música.

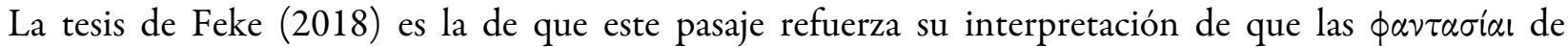
5.1 contienen los teoremas: dado que las matemáticas hacen a quienes las practican más clarividentes

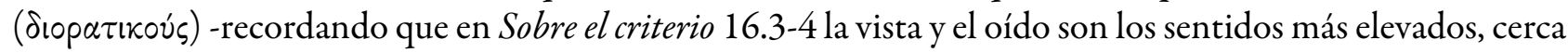
del $\dot{\eta} \gamma \varepsilon \mu o v ı$ cóv-, $^{34}$ esta clarividencia es referida tanto al plano teorético gracias al poder de la vista, el sentido más racional (recordemos que también nos vincula a la belleza), ${ }^{35}$ como al plano práctico ("respecto a la conducta correcta en las acciones y el carácter", Almagesto 1.1, 7.17). La transición de un plano a otro se realiza, según Feke, de manera poco clara, y quizá sea una metáfora. ${ }^{36}$ En cualquier caso, la vinculación entre matemáticas y acciones con el objetivo de la kalokagathía está explicitada en un pasaje coadyuva a la tesis de Feke, Harmónica 3.4, 95.2-3, “(...) [las matemáticas], que tienden al orden que sobreviene como consecuencia del conocimiento teórico a quienes las ejercitan”. De este modo, finalmente, la filosofía teórica y la práctica no están separadas completamente (como se afirma en Almagesto 1.1,4.7) sino que la primera tiene consecuencias en la disposición psicológica del individuo y, por tanto, en sus acciones, que serán mejores.

Hasta aquí, la interpretación de Feke. Es necesario, sin embargo, señalar que la introducción de las $\phi \alpha \nu \tau \alpha \sigma i \alpha \iota$ como instancia que recoge los teoremas para conseguir la kalokagathia constituye, a nuestro juicio,

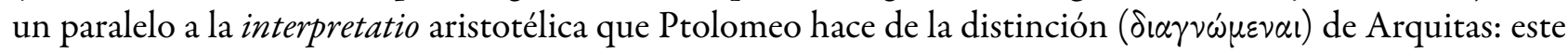
pitagórico también sostuvo en el fragmento citado que quienes se ocupan de $\tau \dot{\alpha} \mu \alpha \theta \dot{\eta} \mu \alpha \tau \alpha$ son capaces de "ver 
correctamente”. Este tipo de contemplación, presente en Platón, aparece en el sumario platónico de Alcínoo referida a la disponibilidad que confieren las matemáticas para la visión del ser (privilegio de la dialéctica). ${ }^{37}$ Jugando con el significado ambiguo de mathémata ("saberes" y "matemáticas"), ${ }^{38}$ Ptolomeo conduce la representación referida a los teoremas $(\alpha \dot{\tau} \tau \tilde{\omega} v)$ mediante la $\phi \alpha \nu \tau \alpha \sigma^{\prime} \alpha$ entendida como impresión de los sentidos, hacia la praxis y las virtudes éticas a partir del esquema formulado por Arquitas (para quien "ver correctamente cómo son las cosas en sus partes" es consecuencia de una correcta y previa distinción), pero solo a partir de las matemáticas; como en Arquitas el "ver

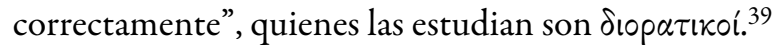

En segundo lugar, la idea de la relación entre los teoremas y el desarrollo en el aspecto práctico también es formulada por Alcínoo (Didascálico 30. 3). Este autor desarrolla una distinción entre virtudes "predominantes" y "subsidiarias": ${ }^{40}$ las primeras están vinculadas con la parte racional del alma mientras que las segundas, sin elemento racional en ellas, alcanzan la belleza solo cuando están de acuerdo con la razón y por medio del hábito y la ejercitación. Como en Almagesto, estas virtudes no son enseñables, pero a partir de

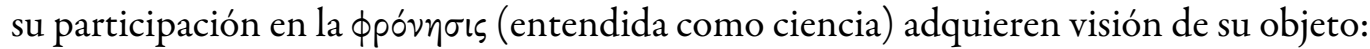

Y puesto que no existe ni ciencia ni arte en ninguna otra parte del alma que no sea tan solo en la racional, las virtudes relativas a la parte afectiva no son enseñables, porque ni son artes ni son ciencias (pues no tienen un objeto propio de estudio). Sin embargo la prudencia, como ciencia, otorga a cada virtud de su propio objeto, igual que el piloto instruye a los marinos en aquello que no ven, y ellos lo obedecen (Alcínoo, Didascálico 30.3).

El planteamiento aquí es el mismo que en el final del proemio ptolemaico. Mientras que en 4.17 el progreso ( $\pi$ poко $\left.\eta^{\prime}\right)$ se da en la teoría, en Alcínoo tiene lugar en el ámbito de la virtud (30.1). Es la virtud predominante de la prudencia, la más racional, ${ }^{41}$ la que provee al conjunto de las virtudes -las de la parte afectiva del alma y no sujetas a instrucción, sino a hábito y ejercitación, cf. Aristóteles, Ética a Nicómaco 2.1- sus propios objetos

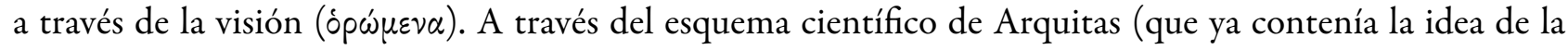
visión), Ptolomeo ha desarrollado uno propio en el que incorpora el material estoico relativo a la percepción ( $\left.\alpha \nu \tau \alpha \sigma^{\prime} \alpha \iota\right)$, que ya se encontraba en la organización del platonismo de época imperial relativa a las virtudes y su jerarquización.

El texto citado de Alcínoo es relevante por cuanto muestra un complejo de ideas a disposición de Ptolomeo y de procedencia diversa. Pero es interesante señalar, asimismo, que la vinculación entre los números y la

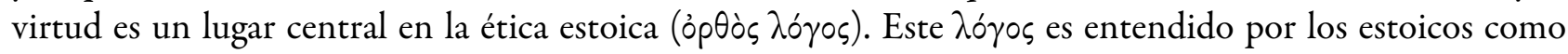
inherente no solo a la virtud sino también a las estructuras matemáticas de la música, y es expresado en la ética estoica como los “números de la virtud” (cf. SVF III 500; Cicerón, Sobre elsupremo bien y el supremo mal 3.24). Es evidente, pues, la conexión que se establece entre estos números, la racionalidad del alma y la disposición virtuosa de esta como una serie de estructuras matemáticas bien armonizadas que adoptan la forma musical de intervalos consonantes. El $\kappa \alpha \tau o ́ p \theta \omega \mu \alpha$ estoico con sus "números" es el equivalente de la prudencia en cuanto que ciencia y se desarrolla en Ptolomeo (cf. Aristides Quintiliano 3.16) ${ }^{42}$ como correspondencias entre consonancias y virtudes. En suma, el paso ptolemaico entre la teoría considerada como matemáticas y la vida práctica regida por ellas contiene in nuce la reformulación estoica que está muy presente, como se ha visto, en su concepto de representación.

Por último, cabría aducir un indicio de cómo Ptolomeo entendería este trasvase de lo teórico a lo práctico. En Harmónica 3.7, el alejandrino acepta la tradicional doctrina griega de los efectos de la música sobre el alma, conocida desde el pitagorismo antiguo. Ahora bien, esta doctrina, divulgada entre los poetas desde época arcaica, encontró en los pitagóricos una sistematización que incluía, probablemente, una justificación basada en las matemáticas (las razones interválicas), de acuerdo con Aristóxeno, fr. 126 (Wehrli, 1945). Consecuente con su orientación platónico-pitagórica en la ciencia harmónica, Ptolomeo acepta esta doctrina y establece un "parentesco" entre alma y organización melódica: 
Por tanto, nuestra alma se compadece manifiestamente con la misma actividad melódica, como si reconociera el parentesco de las razones interválicas de su particular organización, y fuera moldeada por ciertos movimientos propios de las características de la melodía (Harmónica 3.7).

Es importante señalar que para Ptolomeo la música se organiza a través de $\lambda o ́ \gamma o$ interválicos expresados numéricamente (al contrario que en la escuela peripatética a partir de Aristóxeno). Estas razones son las mismas que las de los movimientos celestes, como se comprueba en Harmónica 3.8-12 (capítulos dedicados a las equivalencias entre las estructuras harmónicas y celestes), ${ }^{43}$ y comparten las características que se adujeron respecto a las matemáticas: proporcionalidad y orden (cf. 3.3). El alma, pues, se "compadece" con los $\lambda o ́$ o porque ella misma presenta una estructura reductible a números, como hemos visto en los "números" estoicos. ${ }^{44}$ Volviendo al proemio del Almagesto, la operación sería equivalente: las matemáticas conducen a la excelencia práctica y la virtud, esto es, una modificación del alma, igual que "la total disposición del filósofo es semejante a la armonía total del Sistema perfecto, pues la comparación entre sus partes se establece conforme a las consonancias y las virtudes". ${ }^{45}$ La belleza de los objetos de estudio de la filosofía teórica (cf. Almagesto 1.1

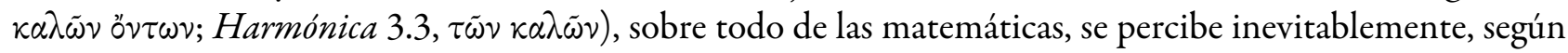
Ptolomeo, mediante los $\lambda$ ó $\gamma$ or armónicos:

Y como es inevitable que quien estudie estas relaciones se quede inmediatamente admirado (si también lo hace con otras formas de belleza) de la facultad armónica, de cómo es la más racional descubriendo con total exactitud y produciendo las diferencias entre las formas apropiadas (...) (Harmónica 3.3).

A continuación, este conocimiento teórico de los $\lambda o ́$ yo pasa a la "subsiguiente pericia en el hábito". La belleza, en fin, de las matemáticas -que según Ptolomeo permite casi "contemplar el género divino"- pasa a las acciones humanas:

(...) pero la belleza o fealdad nadie las juzgaría propias del tacto, del gusto o del olfato, sino solo de la vista o el oído, como la forma y la melodía, o los movimientos de los cuerpos celestes y las acciones humanas (Harmónica 3.3, 93.20-23).

En suma, Ptolomeo se muestra como un platónico cuando refiere la belleza inherente a las matemáticas y la estructura matemática del universo al tiempo que aristotélico, ${ }^{46}$ como demuestra Feke (2018, pp. 87-88), pero a través del material común de la filosofía de su tiempo (tanto estoica como medioplatónica, partiendo de un esquema pitagórico), logra un modelo propio en el que la división entre lo teórico y lo práctico, postulada al comienzo, revela su profunda interrelación y la dependencia del ámbito ético respecto al teórico, en una invitación muy particular al estudio de la astronomía matemática.

\section{ReFERENCIAS}

Barnes, J. (1999). An Introduction to Aspasius. En A. Alberti y R. W. Sharples (Eds.), Aspasius: The Earliest Extant Commentary on Aristotle's Ethics (pp. 1-50). Berlin-New York: Walter de Gruyter.

Barnes, J. (2007). Peripatetic Epistemology: 100BC - 200AD. Bulletin of the Institute of Classical Studies, 94, 547-562.

Boll, F. (1894). Studien über Claudius Ptolemäus. Ein Betrag zur Geschichte der griechischen Philosophie und Astrologie. Leipzig: Jahrbücher für classische Philologie, supp.

Diels, H. (2010). Doxographi Graeci. Cambridge: Cambridge University Press.

Dillon, J. (1993). Alcinous. The Handbook of Platonism. Oxford: Clarendon.

Dillon, J. (1996). The Middle Platonists. 80 B.C. to A.D. 220. Cornell University Press.

Düring, I. (1934). Ptolemaios und Porphyrios über die Musik. Göteborg: Göteborgs Högskolas Arsskrift.

Fazzo, S. (2012), "The 'Metaphysics' from Aristotle to Alexander of Aphrodisias". Bulletin of the Institute of Classical Studies, 55, 51-68.

Feke, J. (2018). Ptolemy's Philosophy. Mathematics as a way of life. Princeton: Princeton University Press. 
Hamm, E. A. (2011). Ptolemy's Planetary Theory: An English Translation of Book One, Part A of the Planetary Hypotheses with Introduction and Commentary. Toronto: University of Toronto.

Huffman, C. A. (2005). Archytas of Tarentum. Pythagorean, Philosopher and Mathematician King. Cambridge: Cambridge University Press.

Jones, A. (2005). Ptolemy's Canobic Inscription and Heliodorus' observation reports. Sciamus, 6, 53-98.

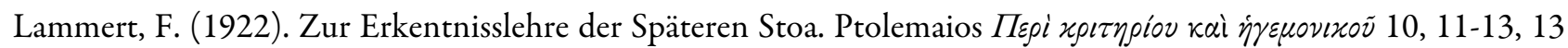
H. Hermes, 57, 171-188.

Long, A. A. (1989). Ptolemy on the Criterion: an Epistemology for the Practising Scientist. En P. Huby y G. Neal (Eds.). The Criterion of Truth. Essay written in honour of George Kerferd together with a text and translation (with annotations) of Ptolemy's On the Kriterion and Hegemonikon (pp. 151-179). Liverpool: Liverpool University Press.

Long, A. A. (1996). The harmonics of Stoic virtue. En A. A. Long, Stoic Studies (pp. 202-223). University of California Press.

Manuli, P. (1981). Claudio Tolomeo: Il Criterio e il principio. Rivista Critica di Storia della Filosofia, 36, 64-88.

Marías, J. (1985). Aristóteles. Ética a Nicómaco (4. ${ }^{\mathrm{a}}$ ed.). Madrid: Centro de Estudios Políticos y Constitucionales.

Mazzarelli, C. (1985). Raccolta e interpretazione delle testimonianze e dei frammenti del medioplatonico Eudoro di Alessandria. Parte prima: testo e traduzione delle testimonianze e dei frammenti sicuri. Rivista di Filosofia NeoScolastica, 77, 197-209.

Mínguez, C. (1995). El Prefacio al Almagesto de Ptolomeo. Themata, 14, 17-35.

Raffa, M. (2002). La Scienza Armonica di Claudio Tolemeo. Saggio critico, traduzione e commento. Messina: Edas.

Raffa, M. (2016). Claudio Tolemeo. Armonica. Con il Commentario di Porfirio. Milano: Bompiani.

Schiefsky, M. J. (2014). The Epistemology of Ptolemy's On the Criterion. En M.-K. Lee (Ed.), Strategies of Argument. Essays in Ancient Ethics, Epistemology, and Logic (pp. 301-331). Oxford: Oxford University Press.

Schönberger, P. L. (1914). Studien zum 1. Buch der Harmonik des Claudius Ptolemaeus. Ein Beitrag zur griechischen Ton- und Musiklehre. Augsburg: Pfeiffer.

Swerdlow, N. M. (2004). Ptolemy's Harmonics and the 'Tones of the Universe' in the Canobic Inscription. En Ch. Burnett, J. P. Hogendijk, K. Plofker y M. Yano (Eds.), Studies in the History of the Exact Sciences in Honour of David Pingree (pp. 137-180). Leiden-Boston: Brill.

Taub, L. Ch. (1993). Ptolemy's Universe. The Natural Philosophical and Ethical Foundations of Ptolemy's Astronomy. Chicago: Open Court.

Tolsa, C. (2013). Claudius Ptolemy and Self-Promotion. A Study on Ptolemy's Intellectual Milieu in Roman Alexandria (Tesis doctorial / Tesis de maestría), Universitat de Barcelona, Barcelona, España. Recuperada de https://www $. t d x . c a t /$ handle $/ 10803 / 128668$ page $=1$

Toomer, G. J. (1984). Ptolemy's Almagest. Princeton: Princeton University Press.

Vander Waerdt, P. A. (1985). Peripatetic Soul Division, Posidonius, and Middle Platonic Moral Psychology. Greek, Roman and Byzantine Studies, 26, 373-394.

Walz, C. (1863). Excerpta de Arte Rhetorica. Vol. 6. Leipzig: Teubner.

Wehrli, F. (1945). Die Schule des Aristoteles. Vol. 2: Aristoxenos. Basel: Schwabe.

\section{Notas}

1 Ptolomeo, Hipótesis 2.4-5, 113-114 H. Cf. Feke (2018, p. 10) y Hamm (2011, p. 218). Platón está detrás de la división del alma de Harmónica 3.5, cf. Raffa (2002, p. 45).

2 Para Fazzo (2012, p. 66), no es sino hasta Alejandro de Afrodisias cuando puede hablarse de un texto de la Metafisica tal como lo conocemos hoy. 
3 Lammert (1922) lo consideraba una fuente de la epistemología del estoicismo tardío, mientras que Manuli (1981) lo vincula con el medioplatonismo y Long (1989) señala su carácter ecléctico; Tolsa (2013) insiste en su platonismo, y Schiefsky (2014) lo considera inserto en la tradición peripatética.

4 Cf. Aristóteles, Metafísica 1026a 18-22, pero es necesario señalar que la triple distinción, así como el carácter intermedio de las matemáticas, es planteado por Posidonio (Plutarco, Sobre la generación del alma en el Timeo 1023B-C) y está presente en Alcínoo, Didascálico 7. En el proemio del Almagesto, Ptolomeo indica que la fuente de la división ternaria de la filosofía teórica es Aristóteles (la misma división aparece en Harmónica 3.3). Ptolomeo trata de ubicar la astronomía como matemáticas, y corregir a) la prelación aristotélica de la teología y b) insistir en la necesidad de instrucción para el saber teórico y no tanto para el práctico.

5 Las traducciones son propias salvo indicación expresa. Hay traducción castellana en Mínguez (1995, p. 23) e inglesa en Toomer (1984, p. 35).

6 Fuentes en Feke (2018, p. 53).

7 Cf. Aristóteles, Sobre el alma 407a 23 ss., 453a 14-15, Política 1333a 24-25, sobre la división bipartita del alma.

8 Cf. Dillon (1993, pp. 59-60), que lleva la distinción en el ámbito práctico a Aristóteles, Ética eudemia $1.81218 \mathrm{~b} 8$ ss., posteriormente interpretada por la praxis escolástica.

9 Para las fuentes, véase Raffa, 2002, p. 457 y n.18 y Dillon, 1993, p. 60.

10 Dillon (1996, p. 122) se refiere a esta mezcla de materiales diversos como una "escolástica platónico-estoica”. En época helenística la clasificación más habitual era en física, lógica y ética (cf. Cicerón, Del supremo bien y el supremo mal 5.9 con la división peripatética pars naturae, disserendi, vivendi).

11 Dillon (1996, pp. 269 y 276) estima que el texto de Alcínoo (autor fechado en torno al siglo II d. C.) podría ser una "nueva edición revisada" de Sobre las doctrinas de Platón, de Ario Dídimo.

12 Dillon (1993, p. 151) considera fuentes del pasaje a Aristóteles, Ética a Nicómaco 1103a 14-18 y Platón, República 518de.

13 Allí las disposiciones que figuran junto a la prudencia, correspondientes a la tríada doméstica, política y ética son tanto prácticas como teóricas; en la distribución de virtudes en las partes del alma, Ptolomeo (Harmónica 3.5) mantiene el mismo planteamiento que Ps. Andronico -aunque en general comparte los esquemas de su época en este aspecto- y presenta ecos de las Definiciones pseudoplatónicas (Boll, 1894, pp. 106-108; Feke, 2018, pp. 59-61).

14 Traducción de Marías (1985, p. 19).

15 Cf. en concreto 1103b 13-25 (sobre todo 24-25). Es de notar que Aristóteles supone para la virtud intelectual la instrucción, y que las virtudes son, en conjunto, para Ptolomeo (4.12) éticas, esto es, las que para Aristóteles proceden

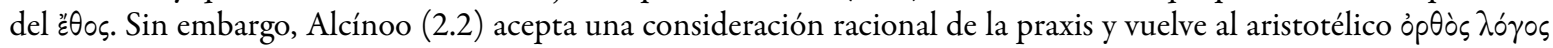
para la consideración teórica de ambas dimensiones; cf. Dillon (1996, p. 276).

16 El pasaje ptolemaico es obscuro. La interpretación de Toomer (1984, p. 35 n.6) a 4.9-10 es que Ptolomeo supone un eventual estadio teórico de la praxis (es decir, de la ética y, por tanto, añadimos, suponiendo que Ptolomeo simplifica las virtudes entendiéndolas todas como prácticas), y lo justifica a la vista de Teón, Comentario al Almagesto p. $320,13$. A nuestro juicio, el pasaje no se desvía de lo que establece Alcínoo en Didascálico 2.1 y es una confirmación de lo que veremos después sobre las consecuencias éticas del estudio matemático. Tolsa (2013, pp. 285-286) propone ver aquí un eco de Antíoco de Ascalón (cf. Cicerón, Del supremo bien y del supremo mal 5.58; Dillon, 1996, pp. 57 ss.), si bien el argumento de Tolsa plantea la actividad teórica "to be the first kind of practical life". Antíoco parece incluir más bien lo teórico como un aspecto más del agere, pero este verbo aquí no implica los objetos de estudio de ambos ámbitos, sino el quehacer humano en general.

17 Düring (1934, pp. 270-272) da como fuente de este pasaje a Espeusipo; Raffa (2016, p. 50) señala también influjos de la literatura neopitagórica, pero también los estoicos dividieron el begemonikón en siete partes, cf. Diels (2010, p. 410). Estas virtudes son las intelectuales tratadas por Aristóteles en Ética a Nicómaco 1140 a 23 ss. y 1142b. Desde Platón (República 436a, 581b) la parte racional del alma está conectada con $\mu \alpha \nu \theta \alpha \dot{\nu \varepsilon เ v . ~}$

18 Cf. Aspasio, Comentario a la Ética Nicomaquea 25.22-23 y 37.9-11.

19 Cf., por ejemplo, Nicómaco, Introducción a la aritmética 1.23, 4-5.

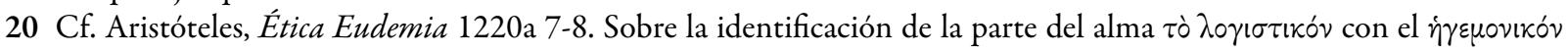
estoico puede decirse que en el siglo II d. C. estaba totalmente consumada, después de que Estratón modificase la partición de Aristóteles del alma (cf. Diels, 2010, p. 394) y algunos peripatéticos adoptaran esta denominación, que también aparece en textos platonizantes. Cf. Vander Waerdt (1985, p. 377 n.16).

21 Eudoro (fr. 9 Mazzarelli, 1985) también se centra en las matemáticas aludiendo a Diodoro de Alejandría.

22 Cf. Epicteto, Disertaciones 2.23.42, con una fórmula que guarda similitudes con la ptolemaica.

23 Sobre el léxico común, cf. Long (1989, p. 155). Lo propio puede decirse desde los mismos comentaristas aristotélicos, cf. Barnes (1999, p. 5). 
24 Cf. Diógenes Laercio 10.31 y 51. Sin embargo, Ptolomeo, en Sobre el criterio 4.3-6 (un pasaje relativo al origen del lenguaje), sigue de cerca a Epicuro (Diógenes Laercio 10.75-76), más que utilizar eclécticamente léxico de procedencia diversa.

25 Cf. Diógenes Laercio 10.31, 10.147. Por otra parte, la imagen, asociada a la representación ( $\left.\phi \alpha \tau \tau \sigma \sigma^{\prime} \alpha\right)$, ya se encuentra en Platón, Filebo 39b.

26 Cf. Platón, República 500 d-e (å દ̇keĩ ópã); cf. Alcínoo, Didascálico 2.2; Dillon (1993, p. 56), Feke, (2018, pp. 64-65).

27 Cf. Ptolomeo, Harmónica 3.5, p. 97.19, y Plutarco, Sobre la generación del alma en el Timeo 1025d-e, Platón, Fedón 68c-69c, 79d. Para el análisis, Dillon (1993, p. 55).

28 Teón, Comentario al Almagesto 321, 8. También, más tarde, David (Prolegómenos 71.10 ss.) supondrá la posibilidad de

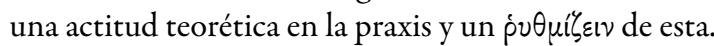

29 Cf. Mazzarelli (1985, pp. 198-199=. Sobre Eudoro y el “impulso", cf. Dillon (1996, p. 122).

30 Cf. $S V F$ III 1 y 169; II 836.

31 SVF III 175; Cicerón, Sobre los oficios 1.132.

32 Traducción modificada a partir de Mínguez (1995, pp. 31-32).

33 Cf. Alcínoo, Didascálico 28.3; Dillon (1993, pp. 172-173).

34 Cf. Sobre el criterio 15.2, p.22.1 L. También en Harmónica 3.3 la vista y el oído están ligados al hegemonikón y tiene que ver con la parte racional del alma. Cf. Diels (2010, p. 391).

35 Cf. Ptolomeo, Harmónica 3.3, 93.11-14. Por lo demás, en Harmónica la "razón representativa" produce orden y proporción en el género visual; cf. Porfirio, Comentario a la Harmónica 13.29-30 (Raffa, 2016, p. 717 n. 55).

36 Algunos presocráticos ya postularon la equivalencia entre intelecto y alma, cf. Diels (2010, p. 392).

37 Cf. Alcínoo, Didascálico 7.4, "el estudio de las matemáticas, pues, es como un preludio a la contemplación de las cosas; en efecto, aunque se esfuerzan por llegar al ser, la geometría, la aritmética y las que las siguen están no hacen sino soñar con lo que existe, pero serán incapaces de contemplarlo en vigilia" (la fuente de este pasaje es Platón, República 533c).

38 Esto es una apreciación de Tolsa (2013, p. 280).

39 En Harmónica 3.5 la capacidad de la clarividencia está relacionada con la presencia, en la parte racional del alma, de la

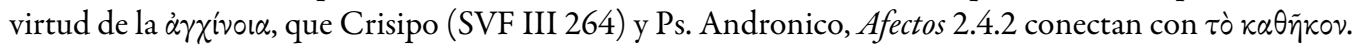

40 Dillon (1993, p. 185) indica la procedencia estoica de esta terminología, cf. SVF II 1157 y III 116; también es estoica la idea de la condición de ciencia de la única virtud racional.

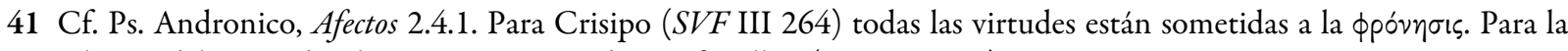
relación del pasaje de Alcínoo con Ario Dídimo, cf. Dillon (1993, p. 185.)

42 Para Long (1996, p. 214), es necesario admitir que la teoría musical estoica estaba fundada sobre el pitagorismo.

43 Desgraciadamente, el capítulo 3.15 está perdido, pero su epígrafe muestra claramente que las razones musicales y los movimientos planetarios son equivalentes. Estas razones verosímilmente se leen en su Inscripción de Canobo 14 ss.; cf. Swerdlow (2004, pp. 165-178) para este pasaje y Jones (2005, pp. 91 ss.).

44 Cf. la división del alma y su equivalencia con los $\lambda o ́$ yo en 3.5, 96.1 ss.; para un análisis de la similitud entre cada parte del alma y cada consonancia, Feke (2018, p. 99).

45 Cf. Ptolomeo, Harmónica 3.5, 97.33-98.1.

46 Cf. Platón, Timeo 28 a-b, Filebo 64e; Aristóteles, Metafísica 1078a 31 ss. 